\title{
Associations between resources and practices of ILD centers and outcomes in patients with idiopathic pulmonary fibrosis: data from the IPF-PRO Registry
}

Joao A. de Andrade ${ }^{1 *}\left(\mathbb{D}\right.$, Tejaswini Kulkarni ${ }^{2}$, Megan L. Neely ${ }^{3,4}$, Anne S. Hellkamp ${ }^{3,4}$, Amy Hajari Case ${ }^{5}$, Daniel A. Culver ${ }^{6}$, Kalpalatha Guntupalli ${ }^{7}$, Shaun Bender ${ }^{8}$, Craig S. Conoscenti ${ }^{8}$ and Laurie D. Snyder ${ }^{3,4}$ on behalf of the IPF-PRO Registry Investigators

\begin{abstract}
Background: Performance benchmarks for the management of idiopathic pulmonary fibrosis (IPF) have not been established. We used data from the IPF-PRO Registry, an observational registry of patients with IPF managed at sites across the US, to examine associations between the characteristics of the enrolling sites and patient outcomes.

Methods: An online survey was used to collect information on the resources, operations, and self-assessment practices of IPF-PRO Registry sites that enrolled $\geq 10$ patients. Site variability in 1-year event rates of clinically relevant outcomes, including death, death or lung transplant, and hospitalization, was assessed. Models were adjusted for differences in patient case mix by adjusting for known predictors of each outcome. We assessed whether site-level heterogeneity existed for each patient-level outcome, and if so, we investigated potential drivers of the heterogeneity.

Results: All 27 sites that enrolled $\geq 10$ patients returned the questionnaire. Most sites were actively following $>100$ patients with IPF (70.4\%), had a lung transplant program (66.7\%), and had a dedicated ILD nurse leader (77.8\%). Substantial heterogeneity was observed in the event rates of clinically relevant outcomes across the sites. After controlling for patient case mix, there were no outcomes for which the site variance component was significantly different from 0 , but the $\mathrm{p}$-value for hospitalization was 0.052 . Starting/completing an ILD-related quality improvement project in the previous 2 years was associated with a lower risk of hospitalization (HR $0.60[95 \% \mathrm{Cl} 0.44,0.82] ; \mathrm{p}=0.001$ ).
\end{abstract}

Conclusions: Analyses of data from patients with IPF managed at sites across the US found no site-specific characteristics or practices that were significantly associated with clinically relevant outcomes after adjusting for patient case mix.

Trial registration ClinicalTrials.gov, NCT01915511. Registered 5 August 2013, https://clinicaltrials.gov/ct2/show/NCT01 915511

Keywords: Interstitial lung disease, Pulmonary fibrosis, Health resources, Hospitalization, Tertiary healthcare

*Correspondence: joao.de.andrade@vumc.org

${ }^{1}$ Vanderbilt University School of Medicine, Nashville, TN, USA

Full list of author information is available at the end of the article

\section{Introduction}

Idiopathic pulmonary fibrosis (IPF) is a progressive interstitial lung disease (ILD) associated with decline in lung function and high mortality [1]. Although international guidelines for the diagnosis and management of IPF have original author(s) and the source, provide a link to the Creative Commons licence, and indicate if changes were made. The images or other third party material in this article are included in the article's Creative Commons licence, unless indicated otherwise in a credit line to the material. If material is not included in the article's Creative Commons licence and your intended use is not permitted by statutory regulation or exceeds the permitted use, you will need to obtain permission directly from the copyright holder. To view a copy of this licence, visit http://creativecommons.org/licenses/by/4.0/. The Creative Commons Public Domain Dedication waiver (http://creativeco mmons.org/publicdomain/zero/1.0/) applies to the data made available in this article, unless otherwise stated in a credit line to the data. 
been published by the American Thoracic Society (ATS), European Respiratory Society (ERS), Japanese Respiratory Society (JRS), and Latin American Thoracic Association (ALAT) [1-4], performance benchmarks for centers diagnosing and managing these patients have not been established. A retrospective study conducted at a single US center found that greater adherence to a bundle of care based on the 2011 ATS/ERS/JRS/ALAT guidelines was associated with improved transplant-free survival after adjustment for age and forced vital capacity (FVC) at baseline [5]. However, there remain few data on how site-specific management practices and resources relate to outcomes in patients with IPF. We hypothesized that the resources, procedures, or organizational characteristics of the sites at which patients with IPF are managed may influence outcomes.

The IPF-PRO Registry (NCT01915511) is an observational multi-center US registry that has enrolled patients with IPF at pulmonary clinics across the US [6]. Registries provide an opportunity to compare practices and outcomes across enrolling centers to generate evidence that may improve clinical care. Previous analyses of data from the IPF-PRO Registry identified a number of patient characteristics that were associated with death or lung transplant $[7,8]$. We used data from this registry to describe the enrolling centers' characteristics and to assess associations between these characteristics and patient outcomes.

\section{Methods}

The design of the IPF-PRO Registry has been published [6]. Briefly, patients with IPF that was diagnosed or confirmed at the enrolling center in the past 6 months were eligible for enrollment. Patients who were participating in a randomized clinical trial or listed for lung transplant could not be enrolled, but patients could participate in a clinical trial or be listed for lung transplant after enrollment. A total of 1002 patients were enrolled at 46 sites (as listed in the "Acknowledgments") between June 2014 and October 2018. For this analysis, data were extracted from the database in March 2020.

An online survey was used to gather information on the resources, operations, and self-assessment practices of all sites that had enrolled $\geq 10$ patients. The survey was developed by adapting the framework used by the US Cystic Fibrosis Foundation clinical benchmarking project [9]. The threshold of 10 patients was selected to ensure that reliable site-level estimates were obtained. Sites completed the questionnaire between 5 February and 1 June 2020, and were instructed to report on their practices and resources prior to the COVID-19 pandemic. Responses based on continuous variables are presented as median (25th percentile, 75th percentile) and categorical variables are presented as number and percentage of sites. The characteristics of patients enrolled at sites included versus not included in this analysis are presented descriptively.

For every site included in the analysis, we estimated the 1-year event rate of the following outcomes from the time of enrollment: (i) death or lung transplant; (ii) hospitalization; (iii) decline in $\mathrm{FVC} \geq 10 \%$ ( $\mathrm{mL}$ or \% predicted), decline in diffusing capacity of the lungs for carbon monoxide (DLco) $\geq 15 \%(\mathrm{mmol} / \mathrm{min} / \mathrm{kPa}$ or $\%$ predicted), death, or lung transplant; and (iv) worsening in each patient-reported outcome, death, or lung transplant. The patient-reported outcomes used were the St. George's Respiratory Questionnaire (SGRQ) [10], the Cough and Sputum Assessment Questionnaire (CASAQ) [11], the 12-item short-form survey (SF-12) [12] and the EuroQoL 5-D (EQ-5D) index score and visual analog scale (VAS) [13]. The thresholds for worsening of the patient-reported outcomes, i.e. an increase in SGRQ total score $\geq 7$, increase in SGRQ activity score $\geq 5$, increase in SGRQ impact score $\geq 7$, increase in SGRQ symptoms score $\geq 8$, decrease in CASA-Q cough domains $\geq 11$, decrease in SF-12 mental component summary (MCS) score $\geq 6$, decrease in SF-12 physical component summary (PCS) score $\geq 5$, decrease in EQ-5D index score $\geq 0.06$ and decrease in $\mathrm{EQ}-5 \mathrm{D} \mathrm{VAS} \geq 8$, were based on published estimates for minimal clinically important differences [14-18].

Site-specific event rates were estimated using the Kaplan-Meier method for all outcomes except hospitalization, for which the cumulative incidence function was used. Site variability in event risk was assessed by fitting a Cox proportional hazards model with a random baseline hazard for each site. Baseline hazard can be interpreted as the relative hazard of a patient at a given site meeting the endpoint relative to a patient at another randomly selected site. The models were adjusted for differences in patient case mix by adjusting for known predictors of each outcome. These predictors were identified through modeling of data from all patients in the IPF-PRO Registry (see Additional file 1: Appendix S1 for details). Age, body mass index (BMI), forced expiratory volume in $1 \mathrm{~s}$ $\left(\mathrm{FEV}_{1}\right) \%$ predicted, $\mathrm{FVC} \%$ predicted, DLco \% predicted, oxygen use with activity, oxygen use at rest, coronary artery disease or heart failure at enrollment, and diagnosis of IPF prior to referral to the enrolling center, were included as adjustment variables in the model assessing death or lung transplant. BMI, $\mathrm{FEV}_{1} \%$ predicted and oxygen use at rest at enrollment were included as adjustment variables in the model assessing hospitalization. The presence of clinically significant emphysema on HRCT in the opinion of the investigator at enrollment was included as an adjustment variable in the model assessing 
decline in FVC, death, or lung transplant. Sex, distance to the enrolling site and hospitalization prior to enrollment were included as adjustment variables in the model assessing decline in DLco, death, or lung transplant. Sex and the value of the respective patient-reported outcome at enrollment were included as adjustment variables in the models assessing worsening in a patient-reported outcome, death, or lung transplant.

To generate a valid model fit, sites that enrolled $<25$ patients were grouped. To assess whether site-level heterogeneity existed for each patient-level outcome, we tested whether the variance of a random site effect was $>0$. If there was evidence of site-level heterogeneity, i.e. if the random site effect was $>0$, we investigated potential drivers of the heterogeneity by looking at associations between site practices and outcomes using forward stepwise selection (with an alpha-to-stay of 0.05). That is, covariates were selected one-by-one based on the covariate with the smallest $\mathrm{p}$-value. At each step, the model was adjusted for covariates selected in previous steps, and the selection process terminated when the p-values of all remaining covariates were $>0.05$. In the Cox proportional hazards models, missing data were handled using multiple imputation. The Full Conditional Specification method was used to fill in the missing data five times to generate five complete data sets. Each complete data set was analyzed using standard statistical analyses and the results were averaged to generate the final inferential results. All analyses were conducted using SAS version 9.4 or higher (SAS Institute, Cary, NC).

\section{Results}

All 27 sites that enrolled $\geq 10$ patients and were sent the questionnaire completed it. Twenty-one of these 27 sites were considered academic sites (with a medical school). One site did not complete the section on staffing models. The responses are presented in Table 1 . The majority of sites were actively following $>100$ patients with IPF $(70.4 \%)$ and had a lung transplant program at the site (66.7\%). Most sites had a dedicated ILD nurse leader to coordinate clinical activities (77.8\%), access to a chest radiologist (96.3\%) and access to a lung pathologist (100\%). The median number of ILD physician specialists was 6 . Almost half of the sites (48.1\%) held weekly multidisciplinary conferences to discuss patients. Physicians, nurses and nurse practitioners/physician assistants were the most frequent providers seeing patients in the clinic (Fig. 1). Patients routinely participated in some form of remote monitoring (telehealth, remote pulmonary function tests, electronic medical records held at center, or other forms of remote monitoring) at $22.2 \%$ of the sites. An ILD-related quality improvement project had been started or completed in the last 2 years at $40.7 \%$ of the sites.

The sites that enrolled $\geq 10$ patients provided 920 (91.8\%) of the 1002 patients in the registry. The median (25th percentile, 75th percentile) number of patients enrolled across the 27 sites was $26(19,45)$. Age, FVC, DLco and oxygen use were similar in these patients compared with patients enrolled at sites not included in the analysis (Additional file 1: Table S1).

\section{Site-specific event rates}

Substantial heterogeneity in site-specific event rates was observed (Table 2). The median (Q1, Q3) site-specific 1-year event rates were $9.8 \%(6.3 \%, 17.5 \%)$ for death or lung transplant and $21.3 \%(12.5 \%, 30.8 \%)$ for hospitalization. Similar heterogeneity was observed for the declines in lung function and the composite outcomes that included deterioration in patient-reported outcomes (Table 2).

\section{Association between site practices and patient outcomes}

Twelve sites enrolled between 10 and 25 patients and were grouped in the models. This accounted for $22.2 \%$ of the cohort (204 patients). The responses to the questionnaire from sites that enrolled $<25$ versus $\geq 25$ patients are presented in Additional file 1: Table S2. There were no outcomes for which the site variance component was significantly different from 0 , i.e., there was no significant $(\mathrm{p}<0.05)$ site-level heterogeneity for any outcome after controlling for patient case mix, but the $\mathrm{p}$-value for hospitalization was 0.052 (Table 3 ). When the relationship between site practices and risk of hospitalization was assessed, "starting/completing an ILD-related quality improvement project in the previous 2 years" was associated with a lower risk of hospitalization (HR 0.60 [95\% CI $0.44,0.82] ; \mathrm{p}=0.001$ ) and "patients routinely participate in some form of remote monitoring" was associated with a higher risk of hospitalization (HR 1.46 [95\% CI 1.04, 2.05]; $\mathrm{p}=0.028$ ). After controlling for patient case mix and these site practices, there was no significant site-level heterogeneity for hospitalization $(\mathrm{p}=0.17)$. The responses to the questionnaire from sites with versus without an ILD-related quality improvement project are presented in Additional file 1: Table S3.

\section{Discussion}

We used data from the IPF-PRO Registry to investigate potential associations between the resources and practices of centers with experience in the diagnosis and management of ILD and outcomes in US patients with IPF. To our knowledge, these are the first data investigating such associations. Substantial heterogeneity was observed in the event rates of clinically relevant outcomes across the 
Table 1 Responses to questionnaire from sites $(n=27)$

\section{Number of enrolled patients}

$26(19,45)$

Approximate number of patients with IPF actively followed

$<25$

$25-50$

$51-100$

$>100$

Approximate number of new patient appointments offered each week

$0-5$

$6-10$

$11-15$

$7(25.9)$

$16-20$

$4(14.8)$

$>20$

Number of ILD physician specialists at center (full- or part-time)

Dedicated ILD nurse leader to coordinate clinical activities

$21(77.8)$

Dedicated ILD nurse practitioner or physician assistant that independently sees patients with ILD

Patient calls handled by an ILD registered nurse or nurse practitioner

$17(63.0)$

Most patients managed

By the enrolling site

Co-management with community pulmonologist

By community pulmonologist primarily

Patients routinely participate in some form of remote monitoring

Telehealth

Remote pulmonary function test monitoring

Electronic medical record system-based program at center

Other $^{\mathrm{a}}$

$2(7.4)$

Patients routinely self-monitor their lung function (spirogram) at home

Time within which a patient with acute concern/deterioration can typically be seen

Same/next day if necessary

3 days

1 week

$1-2$ weeks

Other $^{\text {b }}$

Patient management

Each individual physician follows his/her own panel of patients

Team-based clinic (no assigned patients to a provider)

Hybrid model (e.g., individual patients assigned to specific physician but person on call handles all urgent calls)

Frequency of multidisciplinary conference to discuss patients

Weekly

Every other week (twice a month)

Monthly

Quarterly

Never

Format of MDD

In person, all participants in same room

Remote, by conference call

Hybrid, some in room together and others call in

$4(14.8)$

Access to chest radiologist (on site or at associated facility)

$26(96.3)$

Access to lung pathologist (on site or at associated facility)

$27(100)$

Pre-clinic meetings or care planning meetings

Regular scheduled meetings 
Table 1 (continued)

\begin{tabular}{|c|c|}
\hline Number of enrolled patients & $26(19,45)$ \\
\hline As-needed meetings & $6(22.2)$ \\
\hline No meetings & $18(66.7)$ \\
\hline Routinely provide patients with graphs of their lung function while in clinic & $13(48.1)$ \\
\hline Center has support group or refers patients to outside support group & $25(92.6)$ \\
\hline \multicolumn{2}{|l|}{ Support group meets } \\
\hline Weekly & $1(3.7)$ \\
\hline Every other week & 0 \\
\hline Monthly & $17(63.0)$ \\
\hline Quarterly & $6(22.2)$ \\
\hline Twice a year & $1(3.7)$ \\
\hline Team member assigned to patient education & $10(37.0)$ \\
\hline Routinely provides educational materials in clinic & $20(74.1)$ \\
\hline Routinely refers patients to educational websites & $23(85.2)$ \\
\hline Educational program/activity dedicated to patients and caregivers at least once a year & $17(63.0)$ \\
\hline Local registry/database used for research or quality improvement & $18(66.7)$ \\
\hline Started or completed an ILD-related quality improvement project in last 2 years & $11(40.7)$ \\
\hline Outcomes self-assessment process in place & $2(7.4)$ \\
\hline National Institutes of Health (NIH)-funded research in last 2 years (anyone at center or on team) & $18(66.7)$ \\
\hline Center is a member of the Pulmonary Fibrosis Foundation Care Center Network & $24(88.9)$ \\
\hline Institution has a lung transplant program & $18(66.7)$ \\
\hline Written care protocols/clinical pathways for drug safety monitoring & $13(50.0)$ \\
\hline
\end{tabular}

sites. However, after controlling for differences in known predictors of the outcomes, there were no outcomes for which significant site-level heterogeneity existed i.e., there was no evidence that differences in site practices contributed to the heterogeneity in outcomes across the sites. It remains possible that site-level heterogeneity in outcomes would have been observed if sites with greater differences in resources and practices, e.g. larger academic or regional referral expert centers versus smaller community practices, were compared.

Previous studies have suggested that delayed access to a tertiary care center is associated with worse outcomes in patients with IPF or other ILDs. A prospective study of 129 patients with IPF evaluated at a US tertiary care center found that a greater time from onset of dyspnea to evaluation at the tertiary care center was associated with an increased risk of mortality, after adjustment for age, sex, FVC, payer, and educational attainment [19]. Among 247 patients with IPF from two specialist ILD centers in the UK, patients who were reviewed at a specialist center within 12 months of referral had higher FVC and lower mortality than patients who waited longer to be reviewed [20]. Three-year survival was significantly higher among
144 patients with non-IPF ILDs who received care at a specialized ILD clinic supported by a multidisciplinary team than in a historical cohort of 127 patients whose care was provided by pulmonologists without subspecialty training in ILD or at general clinics without specialized nursing support [21]. The implementation of a multidisciplinary care model at a Canadian clinic was associated with a reduction in the rate of respiratoryrelated hospitalizations among patients with IPF [22].

Almost half of the IPF-PRO Registry sites that we surveyed had started or completed an ILD-related quality improvement project in the previous 2 years. Quality improvement projects are designed to improve the safety, effectiveness and experience of patient care by enhancing healthcare system performance [23, 24]. We found that patients at sites that had undertaken an ILD-related quality improvement project had a numerically lower risk of hospitalization. The reasons for this finding are unclear, as the changes that sites made to their practices as a result of participating in the quality improvement project are unknown and there were no site practices that were clearly associated with better outcomes after controlling for differences in patient case mix. 


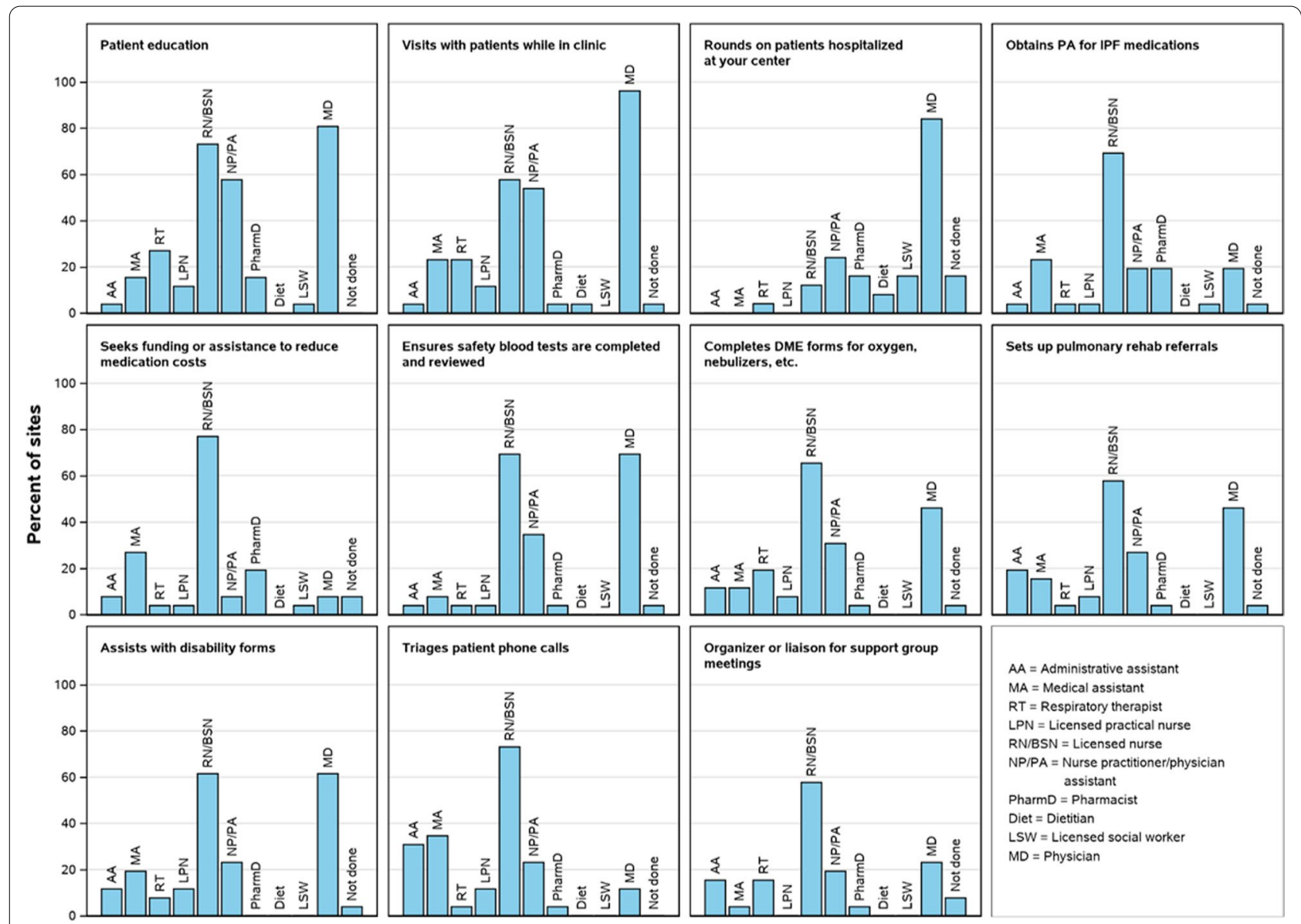

Fig. 1 Site staffing models. Based on data from 28 sites. Data were missing from one site for "Rounds on patients hospitalized at your center". DME durable medical equipment, $P A$ prior authorization

Surprisingly, patients from sites where patients participated in routine remote monitoring had a numerically higher risk of hospitalization. The reason for this observation is unknown. By providing more frequent measurements of lung function, monitoring of FVC through home spirometry may enable earlier detection of disease progression [25], but the evidence to support this is limited. While it is possible that patients who participated in remote monitoring had disease progression detected earlier and so were more likely to be hospitalized, it seems unlikely that patients with IPF who had a deterioration that required hospitalization would not have been hospitalized in the absence of remote monitoring. It is possible that in-person visits associate with additional assessments (e.g., chest CT) that may improve clinicians' comfort not to hospitalize symptomatic patients, or allow earlier intervention that prevents hospitalization.

Strengths of our analyses include the use of a large cohort of patients with IPF enrolled using broad inclusion criteria at multiple sites across the US and adjustment for known predictors of the outcomes. Our analyses also have some limitations. The survey was developed by the research team using the framework of a benchmarking project for a different patient population; however, our survey is aligned with a recently published Delphi survey on the essential components of a specialized ILD clinic [26]. Sites in the IPF-PRO Registry are, in general, regional or national referral centers, which are not representative of all centers at which patients with IPF are managed in the US. It is possible that a study that included more community-based sites as well as referral centers, and so included a greater variety of sites, may have detected associations between site practices and outcomes. The questionnaire used in this study did not collect details of site practices such as quality improvement or palliative care programs. Data on site-specific follow-up and prescription practices were not collected. The use of antifibrotic drugs across the enrolling centers was not assessed in this study, but has previously been 
Table 2 Site-specific event rates of outcomes at 1 year

\begin{tabular}{lc}
\hline & $\begin{array}{c}\text { Median (Q1, Q3) } \\
\text { 1-year event rate } \\
\text { \% }\end{array}$ \\
\hline Death or lung transplant & $9.8(6.3,17.5)$ \\
Hospitalization & $21.3(12.5,30.8)$ \\
Decline in FVC $\geq 10 \%(m L)$ or death or lung transplant & $32.0(21.4,37.5)$ \\
Decline in FVC $\geq 10 \%$ predicted or death or lung transplant & $21.4(13.9,28.5)$ \\
Decline in DLCO $\geq 15 \%$ (mmol/min/kPa) or death or lung transplant & $35.1(26.7,45.7)$ \\
Decline in DLCO $\geq 15 \%$ predicted or death or lung transplant & $15.1(11.1,25.0)$ \\
Increase in SGRQ total score $\geq 7$ or death or lung transplant & $35.3(29.8,43.6)$ \\
Increase in SGRQ activity score $\geq 5$ or death or lung transplant & $48.6(39.2,57.5)$ \\
Increase in SGRQ impact score $\geq 7$ or death or lung transplant & $34.8(30.6,43.5)$ \\
Increase in SGRQ symptoms score $\geq 8$ or death or lung transplant & $35.7(25.8,42.5)$ \\
Decrease in CASA-Q cough impact domain $\geq 11$ or death or lung transplant & $32.3(26.3,39.7)$ \\
Decrease in CASA-Q cough symptoms domain $\geq 11$ or death or lung transplant & $31.4(25.9,36.3)$ \\
Decrease in EuroQoL-5D index score $\geq 0.06$ or death or lung transplant & $37.7(28.6,43.8)$ \\
Decrease in EuroQoL-5D VAS score $\geq 8$ or death or lung transplant & $38.7(29.5,45.8)$ \\
Decrease in SF-12 MCS score $\geq 6$ or death or lung transplant & $28.7(24.0,33.5)$ \\
Decrease in SF-12 PCS score $\geq 5$ or death or lung transplant & $33.5(30.3,40.2)$ \\
\hline
\end{tabular}

CASA-Q cough and sputum assessment questionnaire, DLco diffusing capacity of the lungs for carbon monoxide, FVC forced vital capacity, MCS mental component summary, PCS physical component summary, SF-12 12-item short-form survey, SGRQ St. George's Respiratory Questionnaire, VAS visual analog scale

${ }^{a}$ Cumulative incidence rate for hospitalization; Kaplan-Meier rates reported for all other outcomes

Table 3 Site variability in outcomes (adjusted for differences in patient case mix)

\begin{tabular}{lll}
\hline & $\begin{array}{l}\text { Median }(\mathbf{Q}, \mathbf{Q} \text { Q3) site-level baseline } \\
\text { hazard estimate }\end{array}$ & $\begin{array}{l}\text { p-value for } \\
\text { non-zero } \\
\text { variance }\end{array}$ \\
\hline Death or lung transplant & $0.98(0.92,1.11)$ & 0.28 \\
Hospitalization & $1.06(0.77,1.30)$ & 0.052 \\
Decline in FVC $\geq 10 \%(\mathrm{~mL})$ or death or lung transplant & $0.99(0.94,1.03)$ & 0.29 \\
Decline in FVC $\geq 10 \%$ predicted or death or lung transplant & $1.00(0.97,1.02)$ & 0.52 \\
Decline in DLCO $\geq 15 \%$ (mmol/min/kPa) or death or lung transplant & $0.97(0.94,1.07)$ & 0.11 \\
Decline in DLCO $\geq 15 \%$ predicted or death or lung transplant & $0.99(0.90,1.13)$ & 0.12 \\
Increase in SGRQ total score $\geq 7$ or death or lung transplant & $0.99(0.98,1.01)$ & 0.48 \\
Increase in SGRQ activity score $\geq 5$ or death or lung transplant & $0.99(0.97,1.03)$ & 0.40 \\
Increase in SGRQ impact score $\geq 7$ or death or lung transplant & $0.99(0.97,1.01)$ & 0.40 \\
Increase in SGRQ symptoms score $\geq 8$ or death or lung transplant & $0.99(0.91,1.02)$ & 0.20 \\
Decrease in CASA-Q cough impact domain $\geq 11$ or death or lung transplant & $0.99(0.94,1.05)$ & 0.23 \\
Decrease in CASA-Q cough symptoms domain $\geq 11$ or death or lung transplant & $0.98(0.91,1.06)$ & 0.13 \\
Decrease in EuroQoL-5D index score $\geq 0.06$ or death or lung transplant & $1.00(0.98,1.01)$ & 0.72 \\
Decrease in EuroQoL-5D VAS score $\geq 8$ or death or lung transplant & $1.00(0.97,1.03)$ & 0.60 \\
Decrease in SF-12 MCS score $\geq 6$ or death or lung transplant & $0.99(0.95,1.05)$ & 0.32 \\
Decrease in SF-12 PCS score $\geq 5$ or death or lung transplant & $0.99(0.98,1.01)$ & 0.54 \\
\hline
\end{tabular}

shown to be variable across sites in this registry [27]. The association between antifibrotic drug use and outcomes will be the subject of future work. The patient-reported outcome measures used to assess changes in quality of life in the IPF-PRO Registry were not developed in patients with IPF and have limitations as measures of short-term change. Our analyses were based on site practices prior to the COVID-19 pandemic, which resulted in changes in the use of telemedicine that are unlikely to be entirely reversed. 


\section{Conclusions}

This analysis of data from over 900 patients with IPF managed at sites with experience in the diagnosis and management of ILD across the US found no site-specific characteristics or practices that were significantly associated with clinically relevant outcomes after adjusting for factors known to be associated with these outcomes. Further studies are needed on resources, systems and management practices that may improve outcomes in patients with IPF.

A podcast of Joao de Andrade and Tejaswini Kulkarni discussing these data is available at: https://www.ussci comms.com/respiratory/deAndrade/IPF-PROsitepra ctices

\begin{abstract}
Abbreviations
ALAT: Latin American Thoracic Association; ATS: American Thoracic Society; BMI: Body mass index; CASA-Q: Cough and Sputum Assessment Questionnaire; DLco: Diffusing capacity of the lungs for carbon monoxide; ERS: European Respiratory Society; EQ-5D: EuroQoL 5-D; FEV 1 : Forced expiratory volume in $1 \mathrm{~s}$; FVC: Forced vital capacity; HR: Hazard ratio; ILD: Interstitial lung disease; IPF: Idiopathic pulmonary fibrosis; JRS: Japanese Respiratory Society; MCS: Mental component summary; PCS: Physical component summary; SF-12: 12-item short-form survey; SGRQ: St. George's Respiratory Questionnaire; VAS: Visual analog scale.
\end{abstract}

\section{Supplementary Information}

The online version contains supplementary material available at https://doi. org/10.1186/s12931-021-01921-7.

Additional file 1: Appendix S1. Identification of predictors of clinical outcomes used in adjustment of models. Table S1. Baseline characteristics of patients enrolled at sites included versus not included in the analysis. Table S2. Responses to questionnaire from sites that enrolled $<25$ versus $\geq 25$ patients. Table S3. Responses to questionnaire from sites with versus without an ILD-related quality improvement project.

\section{Acknowledgements}

We thank the principal investigators and enrolling centers in the IPF-PRO Registry: Albert Baker, Lynchburg Pulmonary Associates, Lynchburg, VA; Scott Beegle, Albany Medical Center, Albany, NY; John A. Belperio, University of California Los Angeles, Los Angeles, CA; Rany Condos, NYU Medical Center, New York, NY; Francis Cordova, Temple University, Philadelphia, PA; Daniel A. Culver, Cleveland Clinic, Cleveland, OH; Daniel Dilling, Loyola University Health System, Maywood, IL; John Fitzgerald (formerly Leann Silhan), UT Southwestern Medical Center, Dallas, TX; Kevin R. Flaherty, University of Michigan, Ann Arbor, Ml; Kevin Gibson, University of Pittsburgh, Pittsburgh, PA; Mridu Gulati, Yale School of Medicine, New Haven, CT; Kalpalatha Guntupalli, Baylor College of Medicine, Houston, TX; Nishant Gupta, University of Cincinnati Medical Center, Cincinnati, OH; Amy Hajari Case, Piedmont Healthcare, Atlanta, GA; David Hotchkin, The Oregon Clinic, Portland, OR; Tristan J. Huie, National Jewish Health, Denver, CO; Robert J. Kaner, Weill Cornell Medical College, New York, NY; Hyun J. Kim, University of Minnesota, Minneapolis, MN; Lisa H. Lancaster (formerly Mark Steele), Vanderbilt University Medical Center, Nashville, TN; Joseph A. Lasky, Tulane University, New Orleans, LA; Doug Lee, Wilmington Health and PMG Research, Wilmington, NC; Timothy Liesching, Lahey Clinic, Burlington, MA; Randolph Lipchik, Froedtert \& The Medical College of Wisconsin Community Physicians, Milwaukee, WI; Jason Lobo, UNC Chapel Hill, Chapel Hill, NC; Tracy R. Luckhardt (formerly Joao A. de Andrade), University of Alabama at Birmingham, Birmingham, AL; Yolanda Mageto (formerly Howard Huang), Baylor University Medical Center at Dallas, Dallas, TX; Prema Menon (formerly Yolanda Mageto), Vermont Lung Center,
Colchester, VT; Lake Morrison, Duke University Medical Center, Durham, NC; Andrew Namen, Wake Forest University, Winston Salem, NC; Justin M. Oldham, University of California, Davis, Sacramento, CA; Tessy Paul, University of Virginia, Charlottesville, VA; David Zhang (formerly Anna Podolanczuk, David Lederer, Nina M. Patel), Columbia University Medical Center/New York Presbyterian Hospital, New York, NY; Mary Porteous (formerly Maryl Kreider), University of Pennsylvania, Philadelphia, PA; Rishi Raj (formerly Paul Mohabir), Stanford University, Stanford, CA; Murali Ramaswamy, Pulmonlx LLC, Greensboro, NC; Tonya Russell, Washington University, St. Louis, MO; Paul Sachs, Pulmonary Associates of Stamford, Stamford, CT; Zeenat Safdar, Houston Methodist Lung Center, Houston, TX; Shirin Shafazand (formerly Marilyn Glassberg), University of Miami, Miami, FL; Ather Siddiqi (formerly Wael Asi), Renovatio Clinical, The Woodlands, TX; Barry Sigal, Salem Chest and Southeastern Clinical Research Center, Winston Salem, NC; Mary E. Strek (formerly Imre Noth), University of Chicago, Chicago, IL; Sally Suliman, (formerly Jesse Roman), University of Louisville, Louisville, KY; Jeremy Tabak, South Miami Hospital, South Miami, FL; Rajat Walia, St. Joseph's Hospital, Phoenix, AZ; Timothy P. M. Whelan, Medical University of South Carolina, Charleston, SC.

The authors meet criteria for authorship as recommended by the International Committee of Medical Journal Editors (ICMJE). The authors did not receive payment for development of this article. Writing support was provided by Julie Fleming and Wendy Morris of Fleishman-Hillard, London, UK, which was contracted and funded by BIPI. Boehringer Ingelheim (BI) was given the opportunity to review the article for medical and scientific accuracy as well as intellectual property considerations.

\section{Authors'contributions}

MLN, CSC and LDS were involved in the design of the study. JAdA, AHC, DAC and $\mathrm{KG}$ were involved in data acquisition. MLN and ASH were involved in data analysis. All authors were involved in the interpretation of the data and in the writing and critical review of the manuscript. All authors read and approved the final manuscript.

\section{Funding}

The IPF-PRO/ILD-PRO ${ }^{\mathrm{TM}}$ Registry is funded by Boehringer Ingelheim Pharmaceuticals, Inc. (BIPI) and co-ordinated by the Duke Clinical Research Institute (DCRI).

\section{Availability of data and materials}

The datasets analyzed during the current study are not publicly available, but are available from the corresponding author on reasonable request.

\section{Declarations}

\section{Ethics approval and consent to participate}

The study was approved by the Duke University Institutional Review Board (Pro00046131). The protocol was also approved by the relevant Institutional Review Boards and/or local Independent Ethics Committees prior to patient enrollment at each site listed in the "Acknowledgments". All patients provided informed consent.

\section{Consent for publication}

Not applicable.

\section{Competing interests}

JAdA reports personal fees from BI. TK reports speaker fees from BI. MLN, ASH and LDS are faculty members at DCRI, which receives funding from BIPI to coordinate the IPF-PRO/ILD-PRO Registry. AHC reports personal fees and nonfinancial support from Bl, personal fees from Genentech, and non-financial support from DCRI. DAC reports personal fees from BI and Genentech. KG has nothing to disclose. SB and CSC are employees of BIPI.

\section{Author details}

${ }^{1}$ Vanderbilt University School of Medicine, Nashville, TN, USA. ${ }^{2}$ University of Alabama at Birmingham, Birmingham, AL, USA. ${ }^{3}$ Duke Clinical Research Institute, Durham, NC, USA. ${ }^{4}$ Duke University Medical Center, Durham, NC, USA. ${ }^{5}$ Piedmont Healthcare, Atlanta, GA, USA. ${ }^{6} \mathrm{Cleveland}$ Clinic, Cleveland, $\mathrm{OH}$, USA. ${ }^{7}$ Baylor College of Medicine, Houston, TX, USA. ${ }^{8}$ Boehringer Ingelheim Pharmaceuticals, Inc., Ridgefield, CT, USA. 
Received: 6 May 2021 Accepted: 28 December 2021

Published online: 07 January 2022

\section{References}

1. Raghu G, Remy-Jardin M, Myers JL, et al. Diagnosis of idiopathic pulmonary fibrosis. An official ATS/ERS/JRS/ALAT clinical practice guideline. Am J Respir Crit Care Med. 2018;198(5):e44-68.

2. Raghu G, Collard HR, Egan JJ, et al. An official ATS/ERS/JRS/ALAT statement: idiopathic pulmonary fibrosis: evidence-based guidelines for diagnosis and management. Am J Respir Crit Care Med. 2011;183(6):788-824.

3. Raghu G, Rochwerg B, Zhang Y, et al. An official ATS/ERS/JRS/ALAT clinical practice guideline: treatment of idiopathic pulmonary fibrosis. An update of the 2011 clinical practice guideline. Am J Respir Crit Care Med. 2015;192:e3-19.

4. Jacobs SS, Krishnan JA, Lederer DJ, et al. Home oxygen therapy for adults with chronic lung disease. An official American Thoracic Society clinical practice guideline. Am J Respir Crit Care Med. 2020;202(10):e121-41.

5. Kulkarni T, Willoughby J, Acosta Lara MdP, et al. A bundled care approach to patients with idiopathic pulmonary fibrosis improves transplant-free survival. Respir Med. 2016;115:33-8.

6. O'Brien EC, Durheim MT, Gamerman V, et al. Rationale for and design of the Idiopathic Pulmonary Fibrosis-PRospective Outcomes (IPF-PRO) registry. BMJ Open Respir Res. 2016;3(1):e000108.

7. Snyder L, Neely ML, Hellkamp AS, et al. Predictors of death or lung transplant after a diagnosis of idiopathic pulmonary fibrosis: insights from the IPF-PRO Registry. Respir Res. 2019;20(1):105.

8. Case AH, Hellkamp AS, Neely ML, et al. Associations between patientreported outcomes and death or lung transplant in idiopathic pulmonary fibrosis. Data from the Idiopathic Pulmonary Fibrosis Prospective Outcomes Registry. Ann Am Thorac Soc. 2020;17(6):699-705.

9. Boyle MP, Sabadosa KA, Quinton HB, et al. Key findings of the US Cystic Fibrosis Foundation's clinical practice benchmarking project. BMJ Qual Saf. 2014:23(Suppl 1):i15-22.

10. Jones PW, Quirk FH, Baveystock CM. The St George's respiratory questionnaire. Respir Med. 1991;85 Suppl B:25-31 (discussion 33-37)

11. Crawford B, Monz B, Hohlfeld J, et al. Development and validation of a cough and sputum assessment questionnaire. Respir Med. 2008;102(11):1545-55.

12. Ware J Jr, Kosinski M, Keller SD. A 12-item short-form health survey: construction of scales and preliminary tests of reliability and validity. Med Care. 1996;34(3):220-33.

13. Rabin R, de Charro F. EQ-5D: a measure of health status from the EuroQol Group. Ann Med. 2001;33(5):337-43.

14. Pickard AS, Neary MP, Cella D. Estimation of minimally important differences in EQ-5D utility and VAS scores in cancer. Health Qual Life Outcomes. 2007:5:70

15. Swigris JJ, Brown KK, Behr J, et al. The SF-36 and SGRQ: validity and first look at minimum important differences in IPF. Respir Med. 2010;104(2):296-304

16. Zanini A, Aiello M, Adamo D, et al. Estimation of minimal clinically important difference in EQ-5D visual analog scale score after pulmonary rehabilitation in subjects with COPD. Respir Care. 2015;60(1):88-95.

17. Witt S, Krauss E, Barbero MAN, et al. Psychometric properties and minimal important differences of SF-36 in idiopathic pulmonary fibrosis. Respir Res. 2019;20(1):47.

18. Rebelo P, Oliveira A, Paixão C, et al. Minimal clinically important differences for patient-reported outcome measures of cough and sputum in patients with COPD. Int J Chron Obstruct Pulmon Dis. 2020;15:201-12.

19. Lamas DJ, Kawut SM, Bagiella E, et al. Delayed access and survival in idiopathic pulmonary fibrosis: a cohort study. Am J Respir Crit Care Med. 2011;184(7):842-7.

20. Brereton CJ, Wallis T, Casey M, et al. Time taken from primary care referral to a specialist centre diagnosis of idiopathic pulmonary fibrosis: an opportunity to improve patient outcomes? ERJ Open Res. 2020;6(2):00120-2020.

21. Povitz M, Li L, Hosein $K$, et al. Implementing an interstitial lung disease clinic improves survival without increasing health care resource utilization. Pulm Pharmacol Ther. 2019:56:94-9.
22. Kalluri M, Claveria F, Ainsley E, et al. Beyond idiopathic pulmonary fibrosis diagnosis: multidisciplinary care with an early integrated palliative approach is associated with a decrease in acute care utilization and hospital deaths. J Pain Symptom Manage. 2018;55(2):420-6.

23. Batalden PB, Davidoff F. What is "quality improvement" and how can it transform healthcare? BMJ Qual Saf. 2007;16:2-3.

24. Diamond L, Kues J, Sulkes D. The Quality Improvement Education (QIE) roadmap: a pathway to our future. The alliance for continuing education in the health professions 2015. http://www.acehp.org/d/do/251.

25. Russell AM, Adamali H, Molyneaux PL, et al. Daily home spirometry: an effective tool for detecting progression in idiopathic pulmonary fibrosis. Am J Respir Crit Care Med. 2016;194(8):989-97.

26. Graney BA, He C, Marll M, et al. Essential components of an interstitial lung disease clinic: results from a Delphi survey and patient focus group analysis. Chest. 2020;159(4):1517-30.

27. Salisbury ML, Conoscenti CS, Culver DA, et al. Antifibrotic drug use in patients with idiopathic pulmonary fibrosis. Data from the IPF-PRO Registry. Ann Am Thorac Soc. 2020;17(11):1413-23.

\section{Publisher's Note}

Springer Nature remains neutral with regard to jurisdictional claims in published maps and institutional affiliations.

Ready to submit your research? Choose BMC and benefit from:

- fast, convenient online submission

- thorough peer review by experienced researchers in your field

- rapid publication on acceptance

- support for research data, including large and complex data types

- gold Open Access which fosters wider collaboration and increased citations

- maximum visibility for your research: over $100 \mathrm{M}$ website views per year

At BMC, research is always in progress.

Learn more biomedcentral.com/submissions 